\title{
Will Civil Engineering and Construction SME's benefit from the changes to the 2014 European Procurement Directives
}

\author{
Dr Robert Eadie and Mr Samuel Potts
}

\begin{abstract}
Construction industry fragmentation into nearly a million Small to Medium Sized Enterprises (SME) in the UK led to calls for the European procurement process to be more inclusive. The innovation and skills of these organisations was not being correctly utilized in Government contracts. The introduction of the new procurement directives Europe wide sought to solve this problem. However, the perspective of SME's on issues such as self-declaration provisions, breaking contracts into lots, limits to the financial capacity required, and the effect on procurement if more SMEs tendered had not been fully researched. This paper's findings show an increase in SME involvement as predicted, and that the other elements of the new regulations are appreciated but that organisations have concerns over the capacity of government departments to administer contracts in lots.
\end{abstract}

Keywords - EU Directives,Procurement, Construction

\section{Introduction}

On 11th February 2014 the European Parliament and the Council of the European Union adopted three new directives on public procurement, which are:

- Directive 2014/23/EU on the award of concession contracts [1];

- Directive 2014/25/EU procurement by entities operating in the water, energy, transport and postal services sectors and repealing Directive 2004/17/EC [2], and;

- Directive 2014/24/EU on public procurement and repealing Directive 2004/18/EC [3].

The first of these relates to concession contracts which are defined as contracts with monetary interest but with the devolution of responsibility to a 'economic operator' for the carrying out of works, or to supply and oversee services ([1], para. 11). In Civil Engineering works these are large Public Private Partnership (PPP) schemes which may be in the form of Design Build Finance Operate (DBFO) or Build Operate Transfer (BOT) schemes [4].

With the other two new public procurement directives; 2014/25/EU replaces the previous Utilities Directive and (2014/24/EU) replaces the 2004 version of the Public Procurement Regulations. These are brought into UK law by the Public Contracts Regulations 2015 [5].

The European Commission [6] stated that the aim in providing a revision to the EU directives was to encourage Small Medium Sized Enterprises (SME) involvement and to simplify the process while further guaranteeing sound public procurement procedures. However, the impact of the changes to the regulations in relation to SME's in the UK has not been adequately researched. SMEs are small and medium sized enterprises. The European Union defines a SME as having:

- A maximum of 250 employees and

- An annual turnover of no more than fifty million euro or an annual balance sheet of no more than forty-three million euro [7]. Over 950,000 SMEs operate in the construction industry in the UK in contrast to only 285 large enterprises [8]. Therefore the success of these changes across Europe and in the UK is vital to the construction industry. This research examines the predicted impact of two of the changes: Simplified Selection process and lots.

\section{Simplified selection process}

\section{A. Self-Declaration}

The new regulations adopt a much simpler process of assessing bidders' credentials at the selection stage. The new system allows use of supplier self-declarations with only the preferred bidder requested to submit the required certification and documentation to prove that the contents of the self-declaration were genuine. This change in the regulations assists bidders by allowing the use of a standardised document, Europe wide, named the 'European Single Procurement Document' to self-declare that they have no reason for exclusion from the selection; such as persons in their organisation that have past criminal convictions ([3], para. 84). The European Single Procurement Document', will be valid for six months at a time, and certifies that the bidders have no criminal convictions that would exclude them. Also it would indicate their companies are not insolvent [13]. It can be used instead of a pre-qualification document. However, the quality aspects of the Pre-qualification document are not checked with the exception of ticking certifications.

A 2013 report by the UK Cabinet Office [9] claims, that evidence indicates the removal of prequalification questionnaires for goods and services contracts below the threshold for OJEU notification (during a 2011/12 period), had a significant effect on the speed of procurement and accessibility to SMEs. This supports the view that any measure to reduce the amount of documentation in the procurement process would increase SME involvement.

While the positive aspects of the self-declaration scheme are widely reported, there is a knowledge gap which this research seeks to fill in relation to contractors views on its ability to remove corrupt persons and whether the use of self-declaration over a number of schemes is relevant after the first tender is assessed. Furthermore, this study seeks to 
determine whether tenderers view the self-declaration process as being beneficial.

\section{B. Increased tendering by SME's and the Turnover Requirements Cap}

While the governments across Europe agree that getting SME's increasingly involved in government construction contracts will increase innovation and improve the end product, there has been little research into the impact of increased SME participation on the tendering process.

Requirement for a large organisational financial turnover prior to award in order to ensure that the organisation had enough resources to complete the work is seen as a barrier to smaller SMEs [10]. The new regulations state that Government clients will not be able to set company turnover requirements at more than two times the contract value except where there is a specific justification. Article 58, paragraph 3 of the 'Public Procurement Directive' [3] describes the 'economic and financial standing' limits that authorities could request from bidders. These paragraphs dictate when the imposed limit can be disregarded. This may be due to 'special risks attached to the nature of the works, services or supplies.' In such cases the reasons must be stipulated in either the procurement documents, or a specific report. This suggests that the change increasing the limit typically required from a bidder is beneficial to these SME's. Some analysis anticipates that the lower limit will make it easier for SMEs to tender under the public procurement directives $[11,12]$.

Robin Pressley, a manager at a SME contractor, is cited as stating that placing the limit at the level of two times the contract value as achieving the appropriate level. He does however argue that it would be better still if a firm's solvency were taken into account instead of the turnover [12]. However, research into practitioner's views on the subject was limited prior to this current study with little empirical data provided.

\section{Contract lots}

Prior to the amendment in the regulations, lots were little used in Government construction contracts in the UK. The proposed change was to break the large contracts into smaller portions that could be carried out by smaller contractors but still have a large principle contractor overseeing the works. Prior to the implementation of the new directives much discussion took place on whether the use of lots should be made compulsory with some in support and others suggesting it should be optional or up to the member state [14]. However, on publication of the new directive, Article 47, paragraph 4 of the directive [3] allows a member state to make the dividing of contracts into lots mandatory. The confusion is caused due to leaving it up to individual states to determine whether it is mandatory or not.

The important factor, however, is that in practice there is clarity on the use of lots, and authorities can now limit the amount of lots awarded to a tenderer, subject to having made this clear in the procurement package. The maximum amount to be awarded to one party and the criteria surrounding awarding of multiple lots should be contained in the documentation. This is covered in Article 47, paragraphs 2 and 3 where the government clients are given licence to prohibit the amount of lots a bidder can tender for, or award more than one lot to an 'Economic Operator'.

The provision of a 'do or explain' method for contract lots is explicitly mentioned in Article 47 to encourage member countries to use lots for larger contracts. A justification needs to be provided if the decision is taken not to divide a large contract into lots.

Payment directly to subcontractors (who are normally smaller organisations and have a very high proportion in the SME category) from the Government client in some member states across Europe has also been proposed [10]. This will be subject to the member states introducing mechanisms locally to allow the sub-contractor to challenge unjust payments. However the literature is based on the views of a very small sample and this has not been tested against an industry wide larger sample. This paper seeks to fill this knowledge gap. Furthermore the literature has not examined the impact of the greater administration load on government departments at a time when they are contracting, with less staff to carry out the work.

\section{Method}

The Cabinet Office carried out a consultation on the revised directives and their implementation into UK law via revised Public Contract regulations. They released a document on 30th January 2015, showing the feedback obtained and providing the government response [14]. This document contained two hundred and four responses, but only fifteen of came from businesses (14, pg 3, Table 1). The document does, however, suggest that the views of bidders are clearly of value.

The Central Procurement Directorate website of the Department of Finance and Personnel in Northern Ireland (DFPNI) allowed identification of four hundred and thirtyeight companies who had been awarded Government contracts over the last 5 years. An initial phone and email sift was used to narrow this down to organisations who had been awarded contracts over the European Financial Threshold where the directives apply. This reduced the total population by 99 organisations. However, some refused to take part or respond to either the phone call or email. Of the three hundred and thirty nine remaining, one hundred and seven agreed to take part.

A piloted structured survey was sent to these organisations via the Limesurvey ${ }^{\mathrm{TM}}$ survey package. Of the list of one hundred and seven tenderers who agreed to take part, a total of seventy-one responded to the main survey. Sixteen opted out, three of these expressed via telephone, that after seeing the survey, that it was not applicable to their company. This means that the total relevant participants was one hundred and four organisations. This is beyond the suggested necessary limit for a population of three hundred and thirty-nine, where a sample size of seventy-eight persons is considered acceptable in accordance with a ten percent precision level (Isaac and Michael, 1981; Smith, 1983 cited by Taylor-Powell, 1998, p10) [15]. The final response rate is sixty-eight percent, which is regarded as good, and is close to the very good value of seventy percent prescribed by Rubin and Babbie [16].

The Limesurvey ${ }^{\mathrm{TM}}$ survey package was used to provide automatic statistical analysis of the responses. 
Proc. of the Fourth Intl. Conf. Advances in Civil, Structural and Mechanical Engineering- CSM 2016

Copyright (C) Institute of Research Engineers and Doctors, USA .All rights reserved.

ISBN: 978-1-63248-093-4 doi: 10.15224/ 978-1-63248-093-4-36

\section{v. Findings}

\section{A. Self-Declaration}

Table I indicates the responses as to how successful the self-declaration will be in relation to removal of corrupt persons. It can be seen that the majority $(67.61 \%)$ agree that it is relevant to removal of corrupt persons from the tender.

TABLE I. SELF-DECLARATION AND CORRUPTION

Self-declaration prequalification questions, which remove corrupt persons, will be relevant to the tender

\begin{tabular}{|c|c|c|}
\hline Answer & Count & Percentage \\
\hline Strongly disagree & 3 & $4.23 \%$ \\
\hline Disagree & 3 & $4.23 \%$ \\
\hline Neutral & 13 & $18.31 \%$ \\
\hline Agree & 39 & $54.93 \%$ \\
\hline Strongly agree & 9 & $12.68 \%$ \\
\hline Do not know & 4 & $5.63 \%$ \\
\hline
\end{tabular}

Table II indicates the responses in relation to how relevant self-declaration is to the tender. It can be seen that the majority (67.61\% agree or strongly agree) that it is relevant to the successful outcome of the tender.

TABLE II. SELF-DECLARATION AND RELEVANCY

\begin{tabular}{|c|c|c|}
\hline \multicolumn{3}{|c|}{ The prequalification process is typically relevant to the tender } \\
\hline Answer & Count & Percentage \\
\hline Strongly disagree & 2 & $2.82 \%$ \\
\hline Disagree & 4 & $5.63 \%$ \\
\hline Neutral & 13 & $18.31 \%$ \\
\hline Agree & 40 & $56.34 \%$ \\
\hline Strongly agree & 8 & $11.27 \%$ \\
\hline Do not know & 4 & $5.63 \%$ \\
\hline
\end{tabular}

Table III indicates the responses in relation to how beneficial self-declaration is to the tender. It can be seen that the majority ( $71.83 \%$ agree or strongly agree) that it is beneficial to use this method to show that the organisations comply with the required specifications of the tender.

TABLE III. DOES SELF-DECLARATION ALLOW COMPLIANCE

Self-declarations which will allow organisations to show they comply with the required specifications are beneficial

\begin{tabular}{|c|c|c|}
\hline Answer & Count & Percentage \\
\hline Strongly disagree & 3 & $4.23 \%$ \\
\hline Disagree & 4 & $5.63 \%$ \\
\hline Neutral & 8 & $11.27 \%$ \\
\hline Agree & 40 & $56.34 \%$ \\
\hline Strongly agree & 11 & $15.49 \%$ \\
\hline Do not know & 5 & $7.04 \%$ \\
\hline
\end{tabular}

Table IV indicates by order of preference the benefits of self-declaration from the perspective of tenderers. It can be seen that the reduced time for completing the tender process is the top benefit by number of responses. The resulting capability to complete more tenders in a given timescale is in joint second place along with the reduction in costs to the tenderer. Therefore the efficiency of the process and reduction in costs are seen as the most beneficial aspects of self-declaration.
TABLE IV. IS SELF-DeCLaRATION BENEFICIAL

\begin{tabular}{|c|c|c|}
\hline \multicolumn{3}{|c|}{$\begin{array}{c}\text { In your opinion what affect will a self-declaration process as part of the } \\
\text { selection stage have for the business you represent }\end{array}$} \\
\hline Answer & Count & Percentage \\
\hline reduce time for completing tenders & 45 & $63.38 \%$ \\
\hline aid in completing more tenders & 20 & $28.17 \%$ \\
\hline reduce costs & 20 & $28.17 \%$ \\
\hline reduce complexity & 18 & $25.35 \%$ \\
\hline reduce the resources needed & 16 & $22.54 \%$ \\
\hline little or no effect & 12 & $16.90 \%$ \\
\hline do not know & 10 & $14.08 \%$ \\
\hline
\end{tabular}

\section{B. Impact of increased SME tendering and the Turnover Requirements Cap}

Table $\mathrm{V}$ indicates the responses in relation to SME impact on the tendering process. It can be seen that most consider that it will bring increased competition $(67.61 \%)$. What is worrying is that over a fifth of the respondents consider that it will increase legal challenges.

TABLE V. IMPACT OF SME's ON THE TENDERING PROCESS

\begin{tabular}{|c|c|c|}
\hline \multicolumn{3}{|c|}{$\begin{array}{l}\text { Should more SMEs be tendering, how do you expect this would effect th } \\
\text { tendering process }\end{array}$} \\
\hline Answer & Count & Percentage \\
\hline More competitive & 48 & $67.61 \%$ \\
\hline More legal challenges & 15 & $21.13 \%$ \\
\hline Little or no effect & 12 & $16.90 \%$ \\
\hline Do not know & 6 & $8.45 \%$ \\
\hline
\end{tabular}

Table VI indicates that a third of the respondents had been prevented from tendering because of the financial limits set during the procurement process $(33.80 \%)$.

TABLE VI. FINANCIAL LIMIT PREVENTION FROM TENDERING

Limits [Have the financial capacity requirements prevented the company you represent from tendering or winning tenders in the past]

\begin{tabular}{|c|c|c|}
\hline \multicolumn{2}{|c|}{ you represent from tendering or winning tenders in the past] } \\
\hline Answer & Count & Percentage \\
\hline Yes & 24 & $33.80 \%$ \\
\hline No & 38 & $53.52 \%$ \\
\hline Uncertain & 9 & $12.68 \%$ \\
\hline
\end{tabular}

Table VII indicates that over half of the respondents consider that the new limits will encourage SME's to tender.

TABLE VII. FINANCIAL LIMIT INCENTIVISATION FOR TENDERING

Limits [Do you expect limiting the financial capacity required to a maximum of twice the value of the contract being tender for (except where objectively justifiable) will encourage SMEs to tender] \begin{tabular}{|l|l|l}
\hline Answer & Count & Percentage \\
\hline
\end{tabular}

\begin{tabular}{|c|c|c|}
\hline Answer & Percentage \\
\hline Yes & 37 & $52.11 \%$ \\
\hline No & 7 & $9.86 \%$ \\
\hline Uncertain & 27 & $38.03 \%$ \\
\hline
\end{tabular}

Table VIII indicates that the majority of respondents are unsure $(49.30 \%)$ if the new method of breaking large tenders into lots will result in more SME's winning tenders. However, of those who stated that they knew, double the number considered it would have a positive effect $(33.30 \%)$ than a negative $(16.90 \%)$

TABLE VIII. USE OF LOTS AIDING SME'S IN THE TENDER PROCESS

\begin{tabular}{|c|c|c|}
\hline Limits [Do you expect this limit will aid SMEs in winning tenders] \\
\hline Answer & Count & Percentage \\
\hline Yes & 24 & $33.80 \%$ \\
\hline No & 12 & $16.90 \%$ \\
\hline Uncertain & 35 & $49.30 \%$ \\
\hline
\end{tabular}


Table IX indicates that the majority of respondents are unsure if the new limit is correct (61.97\%). However, of those who responded that they knew, $26.76 \%$ considered it was at the correct level compared to $11.27 \%$ who would have had a different level. This question was followed by an optional qualitative question which analysed the reasons for the responses.

TABLE IX. LOT FINANCIAL LIMIT SET AT CORRECT LEVEL

\begin{tabular}{|c|c|c|}
\hline \multicolumn{3}{|c|}{ Limits [Do you think that this limit is at the correct level] } \\
\hline Answer & Count & Percentage \\
\hline Yes & 19 & $26.76 \%$ \\
\hline No & 8 & $11.27 \%$ \\
\hline Uncertain & 44 & $61.97 \%$ \\
\hline
\end{tabular}

Six responded to the qualitative question. Analysis of the qualitative responses indicates that four of the six respondents consider that the limit should have been set at a more restrictive level. Three of these, deem the contract value should be between twenty and twenty-five percent of a business's annual turnover. These responses are:

1. 'The annualised contract value should be less than $25 \%$ of the tenderer's annual turnover.'

2. 'dependant on contract duration- up to four times'

3. 'At least 5 times the contract or on very large jobs revenue in access of $£ 5$ million...'

It can be seen above that one respondent considers this tighter restriction appropriate only for higher value contracts over five million pounds. One further respondent regards the correct level to be a more restricting third of the annual turnover: 'The limit needs to be defined better to reflect the ANNUAL turnover of the organisation versus the ANNUAL value of the contract (which should be set at a ratio of 3:1)' Finally two respondents consider that the limit should be further reduced to the value of the contract. Analysis determined that these came from companies at the smaller end of the SME spectrum and therefore an amount of personal bias may be evident. However, while these views are interesting they are a minority viewpoint and the limit set in the directives has more support.

\section{The use of Lots}

Table $\mathrm{X}$ indicates that the majority of respondents are unsure if the new limit is correct $(56.34 \%)$. The majority of those aware of staffing levels within the government client considered that they would not have enough staff to administer lots effectively (29.58\% to $14.08 \%)$.

TABLE X. LOT RESOURCE IMPLICATIONS

Lots [Do you expect government bodies will have enough resources to manage lots effectively]

\begin{tabular}{|c|c|c|}
\hline Answer & Count & Percentage \\
\hline Yes & 10 & $14.08 \%$ \\
\hline No & 21 & $29.58 \%$ \\
\hline Uncertain & 40 & $56.34 \%$ \\
\hline
\end{tabular}

Table XI indicates that the majority of respondents consider that their organisations will benefit from the use of lots $(49.30 \%)$. This is substantially more than those who considered that they would not benefit from their use $(16.90 \%)$.

\section{TABLE XI. BENEFICIAL ASPECT OF LOTS}

\begin{tabular}{|c|c|c|}
\hline \multicolumn{2}{|l|}{$\begin{array}{c}\text { Lots [Do you expect that the company you represent will benefit from } \\
\text { contracts divided into lots] }\end{array}$} \\
\hline Answer & Count & Percentage \\
\hline Yes & 35 & $49.30 \%$ \\
\hline No & 12 & $16.90 \%$ \\
\hline Uncertain & 24 & $33.80 \%$ \\
\hline
\end{tabular}

Table XII indicates that over half of the respondents consider that SME organisations will be able to complete with larger organisations through the use of lots $(50.70 \%)$. This is substantially more than those who considered that lot use would not increase the amount of SME competition $(9.86 \%)$.

TABLE XII. LOTS AND SME COMPETITION

Lots [Will this help small and medium sized enterprises (SMEs) to compete with larger businesses]

\begin{tabular}{|c|c|c|}
\hline Answer & Count & Percentage \\
\hline Yes & 36 & $50.70 \%$ \\
\hline No & 7 & $9.86 \%$ \\
\hline Uncertain & 28 & $39.44 \%$ \\
\hline
\end{tabular}

Table XIII indicates that $40.85 \%$ are unsure as to whether lots will increase tender complexity. The respondents are almost equally divided over whether or not it will increase complexity with slightly more considering that it will not $(32.39 \%$ to $26.76 \%)$

TABLE XIII. LOTS AND TENDER COMPLEXITY

Lots [Do you expect this change will make tendering less complex for

\begin{tabular}{|c|c|c|}
\hline \multicolumn{3}{|c|}{ SMEs] } \\
\hline Answer & Count & Percentage \\
\hline Yes & 19 & $26.76 \%$ \\
\hline No & 23 & $32.39 \%$ \\
\hline Uncertain & 29 & $40.85 \%$ \\
\hline
\end{tabular}

Lastly, Table XIV indicates that over half of respondents consider that there will be an increase in SME's tendering for government work $(60.57 \%)$. Only $4.23 \%$ suggested it would produce a decrease.

TABLE XIV. LOTS AND SME TENDER ACTIVITY

\begin{tabular}{|c|c|c|}
\hline \multicolumn{3}{|c|}{$\begin{array}{c}\text { How will work being broken down into Lots affect the amount of SMEs } \\
\text { tendering for government work? }\end{array}$} \\
\hline Answer & Count & Percentage \\
\hline Significant increase & 3 & $4.23 \%$ \\
\hline Increase & 40 & $56.34 \%$ \\
\hline Little or no change & 14 & $19.72 \%$ \\
\hline Decrease & 2 & $2.82 \%$ \\
\hline Significant decrease & 1 & $1.41 \%$ \\
\hline Do not know & 11 & $15.49 \%$ \\
\hline
\end{tabular}

\section{vi. Conclusions and Recommendations.}

This paper examined two elements of the revised European Union procurement directives: the simplified selection process and contract lots. Under these headings this paper examines four issues which had been inadequately researched in the past: self-declaration provisions, breaking contracts into lots, limits to the financial capacity required, and lastly the effect on procurement if SMEs entered the tender process. 
The findings show that the new self-declaration provision is well received by industry. The majority agree that its adoption will decrease corruption. Furthermore the major benefits are the saving in time and reduction in overall tendering costs. The efficiencies will come at a cost however, as qualitative responses to quality questions at prequalification stage will not be provided on a case by case basis. The findings show that organisations consider that they can adequately show that they can comply with the specification through the self-declaration process and be relevant over the period of the standardised document. This is in direct conflict with the findings of previous research which indicates that it is necessary to have a prequalification process that is bespoke for the actual contract in order to genuinely determine quality and be relevant to the project [17]. Further work will have to determine the perspective of the purchasers in addition to the tenderers to see if this tallies with these findings.

With the addition of more SME organisations to the tender process it becomes more competitive. In relation to breaking larger contracts into lots, again it has been received well by industry with almost half of the organisations expecting it to produce benefits and while the majority were unsure that the limit had been set at the correct level, the remaining responses were more positive than negative. The reduced limit is set to bring down the number being rejected due to financial standing. Therefore individual organisations considered it to be beneficial to all SME's as it increases SME involvement in the tender process. Over a third of organisations state they have been excluded due to financial capacity requirements. The findings show reduction in the limits will increase SME participation as required but industry is unsure that this will increase the number of SME's winning tenders. It will also bring increased competition. However, industry is still unsure about the reduction in complexity. Furthermore, the use of lots was deemed beneficial to SME's and will help them complete. However, the industry is unsure that it will reduce the complexity of the tender process and that Government organisations will have enough resources to meet the increased administrative burden. The changes have therefore been shown to fulfil the goals of the European Commission, regarding encouraging increased SME involvement. However, while it results in a more efficient process, with increased competition, further work will have to determine whether the administrative burden on public sector organisations can be accommodated.

\section{References}

[1] European Parliament and the Council of the European Union, (2014b) Directive 2014/23/EU of the European Parliament and of the Council of 26 February 2014 on the award of concession contracts, Official Journal of the European Union

[2] European Parliament and the Council of the European Union, (2014c) Directive 2014/25/EU of the European Parliament and of the Council of 26 February 2014 on procurement by entities operating in the water, energy, transport and postal services sectors and repealing directive 2004/17/EC, Official Journal of the European Union

[3] European Parliament and the Council of the European Union, (2014a) Directive 2014/24/EU of the European Parliament and of the Council of 26 February 2014 on public procurement and repealing Directive 2004/18/EC, Official Journal of the European Union
[4] Hall, D., de la Motte, R. and Davies, S.(2003), Terminology of Public-Private Partnerships (PPPs), Available on-line at www.epsu.org/IMG/doc/PPPs-defs-2.doc [Accessed February 2016].

[5] The Stationary Office (2015), The Public Contracts Regulations 2015, Available on-line at http://www.legislation.gov.uk/uksi/2015/102/pdfs/uksi_20150102_en. pdf [Accessed February 2016].

[6] European Commission (2014a), Revision of Public procurement Directives - Frequently Asked Questions, Available from http://europa.eu/rapid/press-release_MEMO-14-20_en.htm [Accessed February 2016].

[7] European Commission (2014). What is an SME? Available from: http://ec.europa.eu/growth/smes/business-friendly-environment/smedefinition/index_en.htm [Accessed February 2016].

[8] BIS. (2014). Business population estimates for the UK and regions 2014. Sheffield: Enterprise Directorate Analytical Unit, Department for Business, Innovation and Skills (BIS).

[9] Cabinet Office (2013) Making Government business more accessible to SMEs: two years on, Available on-line at https://www.gov.uk/government/publications/making-governmentbusiness-more-accessible-to-smes-2-years-on [Accessed February 2016].

[10] Curran, P. (2014). A new dawn for public procurement? Agenda NI, March 31, 2014, Available on-line at http://www.agendani.com/anew-dawn-for-public-procurement/ [Accessed February 2016].

[11] Claeson, A. (2014) Modernisation of Public Procurement, Making the public market more competitive and collusion proof? Master Thesis, Lunds Universitet, Available on-line at https://lup.lub.lu.se/studentpapers/search/publication/4459522 [Accessed February 2016].

[12] Stothart C.,(2014) How the EU is shaking up procurement, Construction News September 24, 2014 Wednesday, Available online at http://www.constructionnews.co.uk/analysis/analysis/how-theeu-is-shaking-up-procurement/8669861.fullarticle [Accessed February 2016].

[13] Holden, N. and Pearson, S. (2014) The New EU Procurement Directives, Freeth Cartwright LLP, Available on-line at http://www.freeths.co.uk/content/pages/images/publications/THENE WEUPROCUREMENTDIRECTIVES-2014227-151837.pdf [Accessed February 2016].

[14] Cabinet Office (2015a) Government Response to the Consultation on UK Transposition of new EU Procurement Directives, Public Contracts Regulations 2015. Available from: https://www.gov.uk/government/consultations/transposing-the-2014eu-procurement-directives [Accessed February 2016]

[15] Taylor-Powell, E. (1998) Sampling, University of Wisconsin, Cooperative Extension.

[16] Rubin, A. and Babbie, E. (2009) Essential research methods for social work, Second Edition, Brooks/Cole, Cengage Learning.

[17] Eadie, R (2014) Does Europe need a Specific Prequalification System for Highway Projects? In: Proceedings of the 9th International Conference on Civil Engineering Design and Construction (Science and Practice), Varna, Bulgaria. Научно-технически съюз по строителство в България.

About Author (s) Robert Eadie is Course Director of the MEng/BEng (Hons) Civil Engineering Courses at Ulster University. Prior to academia he had 20 years in industry including 7 years writing contracts above the European threshold for a public sector department. His $\mathrm{PhD}$ relates to ecapability maturity of e-procurement

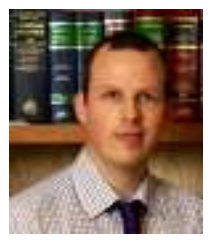

Samuel Potts has worked in the

Construction industry for over 6 years. He has worked for the large multinational organization AMEY who are responsible for large procurements' over the European Threshold. 